\title{
Research Paper: The Immediate Effect of Whole Body $\odot$ (@) Vibration on Core Muscles in Young Healthy Females: A Preliminary Study
}

\author{
Marzieh Beglari Neshat $^{1}$ (D), Azadeh Shadmehr ${ }^{1 *}$ (D), Shohreh Jalaie ${ }^{1}$, Seyed Mohsen Mir ${ }^{1}$, Behrouz Attarbashi Moghadam
}

1. Department of Physiotherapy, School of Rehabilitation, Tehran University of Medical Sciences, Tehran, Iran.

Citation: Beglari Neshat M, Shadmehr A, Jalaie S, Mir SM, Attarbashi Moghadam B. The Immediate Effect of Whole Body Vibration on Core Muscles in Young Healthy Females: A Preliminary Study. Journal of Modern Rehabilitation. 2018; 12(4):239244. http://dx.doi.org/10.32598/JMR.V12.N4.239

doi) http://dx.doi.org/10.32598/JMR.V12.N4.239

Article info:

Received: 13 May 2018

Accepted: 28 Aug 2018

Available Online: 01 Oct 2018

Keywords:

Core stability, Whole body vibration, Immediate,

Semi-squat

\section{A B S T RACT}

Introduction: Previous studies showed that Whole Body Vibration (WBV) is an effective modality for strength and power. WBV has many usages in training and rehabilitation. Core muscles have the central role in the stability of the spine and our daily activity; so, strengthening core muscles is essential. This study aimed to investigate the immediate effect of WBV on strength, endurance, and performance of core muscles in young, healthy females.

Materials and Methods: This study was a quasi-experimental interventional study. Twelve young, healthy females (18-28 years old) participated in this study; they received WBV in semi-squat position 5 times in 60 seconds separated by 30 -second rest. The parameters of WBV included the frequency of $30 \mathrm{~Hz}$ and an amplitude of $4 \mathrm{~mm}$. The tests used for the evaluation of core stability included Vertical Jump (VJ), pressure biofeedback, front abdominal power, trunk extensor endurance, and trunk flexor endurance tests. The tests were performed before, immediately after, and 30 minutes after the intervention.

Results: According to the results, the trunk extensor endurance test, front abdominal power test, and pressure biofeedback had a significant effect $(\mathrm{P}<0.05)$. However, no change was observed in the trunk flexor endurance test and $\mathrm{VJ}$ test $(\mathrm{P}>0.05)$.

Conclusion: This study indicated that WBV could be useful in core stability, specifically for trunk extensor endurance, lumbar strength, and front abdominal power. More studies are required to prove the effect of $\mathrm{WBV}$ on $\mathrm{VJ}$ and trunk flexor endurance.

\section{Introduction}

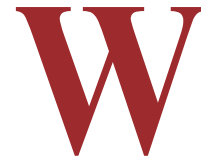

hole Body Vibration (WBV) is a training modality that transmits the vibration to the body through an oscillatory platform [1]. WBV can be adjusted for more efficacies according to some parameters such as frequency, amplitude, duration, and position on the device. Previous studies showed that WBV could be effective in power, balance, strength, flexibility, and warm-up [2, 3]. So,

\footnotetext{
* Corresponding Author: Azadeh Shadmehr, PhD.

Address: Department of Physiotherapy, School of Rehabilitation, Tehran University of Medical Sciences, Tehran, Iran. Tel: +98 (21) 77528468

E-mail:shadmehr@tums.ac.ir
} 
WBV is a mechanical modality that can be effective in muscles and neuromuscular such as core muscles and core stability.

Core muscles are composed of lumbopelvic and hip muscles. According to Kibler's definition, these muscles have "the ability to control the position and motion of the trunk over the pelvis and to allow optimum production, transfer, and control of force and motion to the terminal segment" $[4,5]$. Core muscles have the main role in the stability of the spine in conjunction with neuromuscular control, ligaments, and osseous. Their role in the stability of the spine is seen in our daily activity; so, core strengthening can prevent and reduce the low back pain as this protocol is widely used in the clinics [6].

One of the methods of increasing core stability is the use of WBV, which is of great importance nowadays. In previous studies, it has been proven that WBV increases strength and power, but no study has yet examined the effect of WBV on core muscles and evaluated its strength, function, performance, and endurance through the functional tests. This study aimed to investigate the impact of WBV with the semi-squat position on core muscles through functional tests.

\section{Materials and Methods}

\section{Study participants}

Twelve young, healthy females (Mean \pm SD age: $21.4 \pm 2.3 \mathrm{y}$, height: $165.4 \pm 3.4 \mathrm{~m}$, weight: $60.16 \pm 7.5 \mathrm{~kg}$, and BMI: $21.8 \pm 2.3 \mathrm{~kg} / \mathrm{m}^{2}$ ) participated in this study. Voluntaries participated in this study with no history of acute or chronic low back pain, trauma, injury, or operation in the back, heart disease, epilepsy, hypertension, severe diabetes, kidney stones, and tumors, as well as no problem with the central nervous system.

\section{Study design}

This study was a quasi-experimental interventional study. After the approval of this study by the Ethics Committee of Tehran University of Medical Sciences, the participants entered the study after filling the consent form and the questionnaire. In this study, the participants were evaluated three times: before, immediately, and 30 minutes after the intervention through the functional tests. Core muscles were evaluated through functional tests such as Vertical Jump (VJ), Front Abdominal Power Test (FAPT), Pressure Biofeedback (PB), Trunk Flexor Endurance Test (TFET), and Trunk Extensor Endurance Test (TEET). All of the tests were repeated three times and separated by ten seconds rest. The average of numbers was calculated as the final number.

\section{Core stability tests}

The Vertical Jump (VJ) test started from the squat position with 60 knee flexion near the wall. The subject jumped and recorded a point on the scaled page with his or her right hand (The third finger). The therapist calculated the distance of two points. The first point was the length of the person from the ground to arise hand (The third finger), and the next one was the touched point after jumping.

Pressure biofeedback (PB) Strength measurement was performed by placing a bag of PB device under the back of the subject. The subject was placed in crook-lying position, and the PB device was positioned near the Posterior Superior Iliac Spine (PSIS), while was adjusting on $40 \mathrm{~mm} \mathrm{Hg}$. Then, he or she was asked to perform posterior pelvic tilt and to hold it for three to five seconds. The test was taught and repeated in the event of a mistake.

Front Abdominal Power Test (FAPT), the subject was placed in crook-lying position on the ground and took a medicine ball (one $\mathrm{kg}$ ) by both hands with full flexion of the shoulder over the head. Then, he or she sat up and released the ball. The therapist calculated the distance from toe to the touched point by the ball.

Trunk extensor endurance test (TEET) is one of the McGill endurance tests that evaluates the endurance of extensor back muscles [4]. The subject was placed in the prone position while the trunk and upper extremity were out of the table. Pelvic and shin were fixed by the belt and hands were placed on the chair; then, he or she was asked to release the chair and cross the arms over the chest. The therapist calculated the length of endurance time by a chronometer.

Trunk Flexor Endurance Test (TFET) is one of the McGill endurance tests that evaluates the endurance of flexor abdominal muscles [4]. The subject was placed in crook-lying position and, then, leaned to the wedge in sitting position with $60^{\circ}$ trunk flexion and $90^{\circ}$ knee flexion. The feet were fixed by the belt; then, he or she was asked to hold the position without supporting wedge The therapist calculated the length of endurance time by a chronometer. 


\section{The Study Intervention}

For the intervention, Power Plate-Next Generation machine (The United States) was used. The subject stood on the center of WBV platform in a semi-squat position with $60^{\circ}$ knee flexion while holding his/her hand from the handle of WBV for five times in 60 seconds separated by 30 seconds rest $[7,8]$. The goniometer was used to accurately measure the angle of the knee in semi-squat position on a WBV device. The parameters of WBV included the frequency of $30 \mathrm{~Hz}$, the amplitude of four $\mathrm{mm}$, and the peak acceleration of $14.8 \mathrm{~g}$ through the following formula $[7,9]$ :

$$
A_{\text {peak }}=\omega^{2} a\left(\frac{m}{s^{2}}\right)
$$

$\omega(k 9)$

\section{Data analysis}

The obtained data were analyzed in SPSS V. 17. The Kolmogorov-Smirnov test was used to evaluate the normality of the data $(\mathrm{P}>0.05)$. The repeated measures oneway Analysis of Variance (ANOVA) was used to assess the effect of WBV on core stability before, immediately, and 30 minutes after the intervention $(\mathrm{P}<0.05)$.

\section{Results}

WBV was useful in some variants leading to an increase in core stability (Figure 1). This augmentation was evident according to the $\mathrm{PB}$ test level of strength $(\mathrm{P}=0.002)$, FAPT test of throwing ball distance $(\mathrm{P}=0.002)$, and TEET test of trunk extensor endurance $(\mathrm{P}=0.02)$. However, for $\mathrm{VJ}$ and TFET tests, there was no significant effect after the intervention (Table 1). Post hoc test analysis showed that core stability increased in some parameters as strength $(\mathrm{P}=0.004)$, throwing ball distance $(\mathrm{P}=0.03)$, and trunk extensor endurance $(\mathrm{P}=0.03)$ 30 minutes after the intervention. Also, an increase was observed in the FAPT test $(\mathrm{P}=0.02)$ immediately after the intervention.

\section{Discussion}

This study aimed to investigate the effect of WBV on core stability immediately and 30 minutes after the intervention. Different functional tests were used for a more accurate evaluation of core muscles. The main finding showed that WBV could be effective in some parameters of core stability, such as strength, function, and trunk extensor endurance. The results showed that 30 minutes after WBV, there were significant differences in FAPT, TEET, and PB test, but immediately after the intervention, all variables except FAPT had no significant changes. Fatigue was probably one of the reasons causing no changes in TFET and PB test shortly after the intervention, whereas the quantity of PB and TFET increased to some extent after 30 minutes on the intervention time. However, FAPT and PB evaluate anterior core muscles. The results showed that WBV could be effective in anterior abdominal muscles. Wirth et al. found significant improvement in abdominal muscles with WBV through Electromyography (EMG) [10].

$\mathrm{VJ}$ is a useful test that measures the power and performance of muscles during a jump, and it has been used in many studies $[2,8,11,12]$. Throughout this study, there was no significant change in VJT and TFET. Cochrane et al. and Cormie et al. reported that WBV was effective in VJ, flexibility, and warm-up. The difference between our and Cochrane's study was in the

Table 1. Mean $\pm S D$ of variants before and after the intervention

\begin{tabular}{|c|c|c|c|c|c|}
\hline \multirow{2}{*}{ Variants } & \multicolumn{3}{|c|}{ Mean \pm SD } & \multirow{2}{*}{$\mathbf{P}^{*}$} & \multirow{2}{*}{$\mathbf{F}^{*}$} \\
\hline & Before the Intervention & After the Intervention & Thirty Minutes After the Intervention & & \\
\hline $\mathrm{VJT}(\mathrm{cm})$ & $25.8 \pm 9.1$ & $26.2 \pm 9.3$ & $26.3 \pm 7.8$ & 0.62 & 0.35 \\
\hline PB (mm Hg) & $66.9 \pm 13.3$ & $70.7 \pm 16.4$ & $73.1 \pm 15.2$ & 0.002 & 8.64 \\
\hline FAT $(\mathrm{cm})$ & $199.2 \pm 49.7$ & $208.02 \pm 51.4$ & $210.2 \pm 53.2$ & 0.002 & 8.24 \\
\hline TEET (s) & $46.9 \pm 27.4$ & $51.7 \pm 27.6$ & $56.08 \pm 32.2$ & 0.02 & 4.32 \\
\hline TFET (s) & $71.6 \pm 49.4$ & $82.8 \pm 46.7$ & $79.6 \pm 50.9$ & 0.37 & 1.03 \\
\hline
\end{tabular}

VJT: Vertical Jump Test; PB: Pressure Biofeedback; FAT: Front Abdominal Test; TEET: Trunk Extensor Endurance Test; TFET: Trunk Flexor Endurance Test; "Repeated measurement one-way ANOVA 

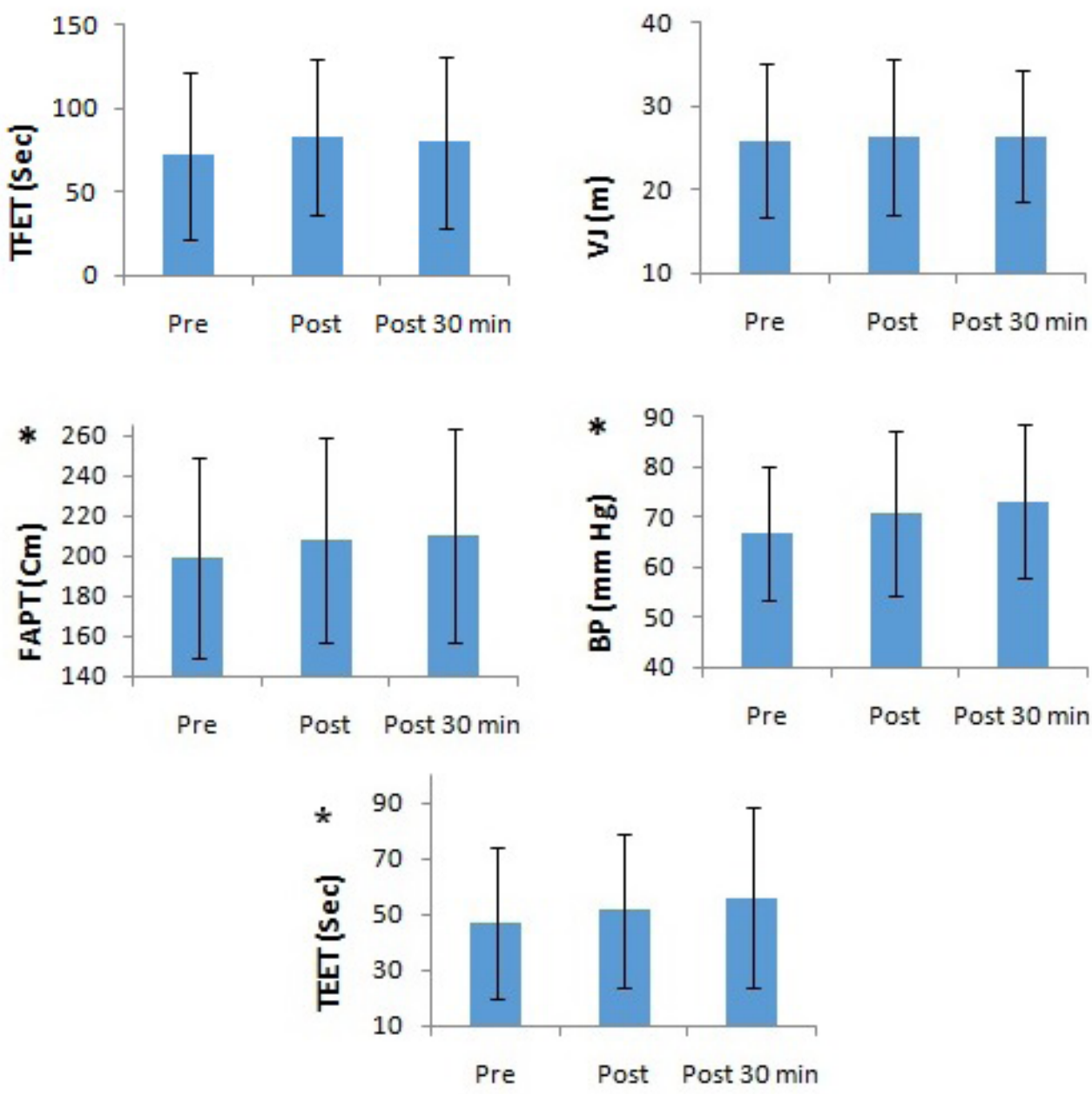

Figure 1. Mean $\pm S D$ of core stability tests of the intervention

study participants and the variety of positions (in the study carried out by Cochrane et al. 6 positions were used, and the participants were hockey players) [12, 13]. Nevertheless, some studies disapproved the effect of WBV on VJ, performance, and isometric strength $[2,8,14]$. In Kurt et al. study, WBV was ineffective in VJ increase in well-trained combat athletes. Studies showed that WBV was more effective in muscles of well-trained athletes. However, it also depends on the parameters of WBV that must be adjusted according to the physical fitness of participants. Mechanical vibration excites the muscle spindles and alpha motor neuron, which causes Tonic Vibration Reflex (TVR).

Furthermore, the exposure of the WBV causes a repetitive eccentric-concentric contraction in the muscles that increases muscles metabolism. So, the mechanism of the acute effect of WBV on muscles is increasing temperature, metabolism of major muscles, and the cause of TVR. Thus, these factors can be effective in various parameters of muscles, including strength and function
$[1,15]$. Although some parameters of core stability increased in this study, there were some restrictions such as the absence of a control group and the low number of participants. Therefore, future studies are recommended to evaluate the effect of WBV on core stability, including the comparison of semi-squat position with other positions and the replacement of ordinary participants with athletes or males; considering the control group for this study is also suggested.

\section{Conclusion}

In conclusion, this study showed that WBV could be effective in core stability, in particular, for trunk extensor endurance, lumbar strength, and front abdominal power, but there was no significant effect in VJ and trunk flexor endurance. More studies are recommended to evaluate the effect of WBV on the core stability in strength, power, performance, and endurance of the muscles. 


\section{Ethical Considerations}

Compliance with ethical guidelines

This study was approved by the Ethics Committee of Tehran University of Medical Sciences.

Funding

The present paper was extracted from the MSc. thesis of the first author, Department of Physiotherapy, School of Rehabilitation, Tehran University of Medical Sciences. (Code: 97-03-32-40054)

\section{Authors contributions}

Methodology, writing and editing: Marzieh Beglari Neshat, Azadeh Shadmehr; Investigation: Marzieh Beglari Neshat, Shohreh Jalaie; Supervision: Seyed Mohsen Mir, Behrouz Attarbashi Moghadam.

\section{Conflict of interest}

The authors declared no conflict of interests.

\section{Acknowledgements}

The authors would like to appreciate Tehran University of Medical Sciences for supporting this study.

\section{References}

[1] Cochrane DJ, Stannard SR, Sargeant AJ, Rittweger J. The rate of muscle temperature increase during acute whole-body vibration exercise. European Journal of Applied Physiology. 2008; 103(4):441-8. [DOI:10.1007/s00421-008-0736-4] [PMID]

[2] Kurt C, Pekünlü E. Acute effect of whole body vibration on isometric strength, squat jump, and flexibility in welltrained combat athletes. Biology of Sport. 2015; 32(2):115-22. [DOI:10.5604/20831862.1134558] [PMID] [PMCID]

[3] Osawa Y, Oguma Y, Ishii N. The effects of whole-body vibration on muscle strength and power: A meta-analysis. Journal of Musculoskeletal and Neuronal Interactions. 2013; 13(3):380-90. [PMID]

[4] Huxel Bliven KC, Anderson BE. Core stability training for injury prevention. Sports Health. 2013; 5(6):514-22. [DOI:10.1177/1941738113481200] [PMID] [PMCID]

[5] Kibler WB, Press J, Sciascia A. The role of core stability in athletic function. Sports Medicine. 2006; 36(3):189-98. [DOI:10.2165/00007256-200636030-00001] [PMID]
[6] Akuthota V, Ferreiro A, Moore T, Fredericson M. Core stability exercise principles. Current Sports Medicine Reports. 2008 7(1):39-44. [DOI:10.1097/01.CSMR.0000308663.13278.69] [PMID]

[7] Maeda N UY, Sasadai J, Miyamoto A, Murakami M, Kato J. Effect of whole-body-vibration training on trunk-muscle strength and physical performance in healthy adults: Preliminary results of a randomized controlled trial. Journal of Sport Rehabilitation 2016; 25(4):357-63. [DOI:10.1123/jsr.2015-0022] [PMID]

[8] Cochrane DJ, Legg SJ, Hooker MJ. The short-term effect of whole-body vibration training on vertical jump, sprint, and agility performance. The Journal of Strength \& Conditioning Research. 2004; 18(4):828-32. [DOI:10.1519/14213.1]

[9] Kim WT, Lee HJ, Tae KS. The trunk muscles activity on whole body vibration during bridging position in young healthy adults. International Journal of Precision Engineering and Manufacturing. 2016; 17(7):949-56. [DOI:10.1007/s12541-016-0116-7]

[10] Wirth B, Zurfluh S, Müller R. Acute effects of whole-body vibration on trunk muscles in young healthy adults. Journal of Electromyography and Kinesiology. 2011; 21(3):450-7. [DOI:10.1016/j.jelekin.2010.12.007] [PMID]

[11] Sharrock C, Cropper J, Mostad J, Johnson M, Malone T. A pilot study of core stability and athletic performance: is there a relationship? International Journal of Sports Physical Therapy. 2011; 6(2):63-74. [PMID] [PMCID]

[12] Cochrane D, Stannard S. Acute whole body vibration training increases vertical jump and flexibility performance in elite female field hockey players. British Journal of Sports Medicine. 2005; 39(11):860-5. [DOI:10.1136/bjsm.2005.019950] [PMID] [PMCID]

[13] Cormie P, Deane RS, Triplett NT, McBride JM. Acute effects of whole-body vibration on muscle activity, strength, and power. The Journal of Strength \& Conditioning Research. 2006; 20(2):257-61. [DOI:10.1519/00124278-200605000-00004] [PMID]

[14] Gerodimos V, Zafeiridis A, Karatrantou K, Vasilopoulou T, Chanou K, Pispirikou E. The acute effects of different wholebody vibration amplitudes and frequencies on flexibility and vertical jumping performance. Journal of Science and Medicine in Sport. 2010; 13(4):438-43. [DOI:10.1016/j.jsams.2009.09.001] [PMID]

[15] Albasini A, Krause M, Rembitzki IV. Using whole body vibration in physical therapy and sport: Clinical practice and treatment exercises. Amsterdam: Elsevier Health Sciences; 2010. 
This Page Intentionally Left Blank 